\title{
FRENTE CONJETURAL: ESCRITORES BRASILEÑOS DE IZQUIERDA Y EL ESTADO NOVO
}

\author{
POR \\ LUIZA F. MOREIRA \\ Department of Comparative Literature \\ Binghamton University \\ (Traductores: Carlos Cortissoz y Sandra Sánchez-López)
}

En el diario oficial del Estado Novo, la dictadura liderada por Getúlio Vargas en Brasil entre 1937 y 1945, un grupo de intelectuales organizaron una sección cultural, "Pensamento da América», dedicada a publicar traducciones de escritores de toda América. Basado en trabajo de archivo, este artículo reconstruye la trayectoria de esta sección cultural, desde un antifascismo y latinoamericanismo más bien en sordina durante 1941, hasta su papel de apoyo a la politica exterior de Vargas durante la guerra, de 1942 en adelante. El artículo se ocupa, sobre todo, de explorar los contextos que abrieron el camino y establecieron los límites para las actividades de los intelectuales responsables de «Pensamento da América».

Palabras clave: Hegemonía, intelectuales en Brasil, Ribeiro Couto, Manuel Bandeira, era Vargas.

${ }^{1}$ Este proyecto surge de mi trabajo previo con Cassiano Ricardo, poeta y periodista brasileño del siglo XX, y la investigación de archivo que está a la base del artículo me ha ocupado desde el 2006. Una discusión preliminar y más corta de este material ha sido publicada en portugués por la revista italiana Rivista di studi portoghesi i brasiliani. He presentado el trabajo en progreso en varias ocasiones: en la Universidad de Texas en Austin, en marzo de 2006, y en reuniones de la Latin American Studies Association (2007), la Brazilian Studies Asociation (2008), la Associação Brasileira de Literatura Comparada (2008) y la American Comparative Literature Association (2009). En todas estas ocasiones, el diálogo con la audiencia me ha ayudado a desarrollar y clarificar mis argumentos. Me gustaría agradecer a César Braga Pinto por su cuidadosa lectura del manuscrito, pero también a Francisco Foot Hardmann y Dale Tomich, quienes me acompañaron en el desarrollo de este proyecto y fueron indefectiblemente generosos en su aliento. Muchas gracias también a Leopoldo Bernucci y Charles Perrone por su apoyo. 
Uno o dos detalles, que a primera vista pueden parecer insignificantes, se hallan en el punto de partida de este artículo. Dos escritores modernistas brasileños bien conocidos y merecidamente admirados, Manuel Bandeira y Cecília Meireles, contribuían con frecuencia al diario $A$ Manhã de Río de Janeiro a principios de la década de 1940 y lo mencionan de pasada. En Itinerário de Pasárgada, una autobiografía intelectual publicada por primera vez en 1945, Bandeira se refiere al diario en unos pocos párrafos dedicados a las traducciones que él reunió en el volumen Poemas Traduzidos. La mayor parte de estas traducciones, el autor especifica, fueron hechas «para cumplir mis deberes como colaborador de "Pensamento da América", un suplemento mensual de $A$ Manhã»». También encontramos numerosas referencias a $A$ Manhã en los volúmenes que reúnen las Crônicas de Educação de Cecília Meireles. Su editor, Leodegário A. de Azevedo Filho, anota que estas breves piezas de prosa se habían publicado inicialmente en el Diário de Notícias de Río de Janeiro entre 1930 y 1933 y, luego, entre 1941 y 1943, en A Manhã. Una selección de las crónicas sobre educación que Meireles escribió para $A$ Manhã llena un volumen de 370 páginas $^{3}$.

Referencias de paso, traducciones, crónicas, un diario — en la perspectiva de la historia de la literatura éstos pueden parecer cuestiones de detalle-. No obstante, me gustaría tomar estas breves referencias no tanto como notas al pie sino más bien como pistas, en un sentido similar al que Carlo Ginzburg le da a esta palabra. La obra de Ginzburg es usualmente recordada en conexión con la práctica historiográfica de la «microhistoria», y su estudio El queso y los gusanos es reconocido como una ilustración admirable de este enfoque. Sin embargo, él ha subrayado que en otros proyectos su perspectiva ha sido «decididamente macrohistórica» ${ }^{4}$. Más que simplemente aplicarse al tipo de investigación histórica que reduce radicalmente su escala de observación, «el paradigma conjetural o semiótico» que le interesa a Ginzburg tiene una amplia influencia en las ciencias humanas. En su opinión, este paradigma interpretativo está a la base de gran parte del conocimiento de los fenómenos humanos en el sentido más amplio, en medicina y psicoanálisis así como en las investigaciones históricas y literarias 5 .

2 Bandeira, 1958, 2: 100.

3 Cecília Meireles fue una asidua colaboradora de $A$ Manhã. Sus crónicas sobre educación, firmadas simplemente con la inicial «C», aparecieron en la sección «Professores y estudantes» casi cada semana. Aunque tiene casi cuatrocientas páginas, el volumen que recopila sus piezas sobre educación, editado por Azevedo Filho, incluye sólo una porción de su obra sobre este tema para $A$ Manhã. Otros volúmenes en la serie de Azevedo Filho, organizada temáticamente, incluyen textos de prosa que fueron también publicados originalmente en $A$ Manhã.

4 Ginzburg, 1993: 32.

5 Estoy en deuda con la lúcida discusión de Henrique Espada Lima de este ensayo y de 
Detalles aparentemente insignificantes, a menudo relegados como notas al pie, sirven en cambio para Ginzburg como las pistas que le permiten al historiador reconstruir una elusiva y fuertemente enmascarada realidad, que no puede ser conocida directamente y permanece inaccesible a través del medio del pensamiento sistemático:

[El paradigma conjetural] puede convertirse en un recurso para disolver las nubes ideológicas que oscurecen cada vez más una compleja estructura social tal como la del capitalismo totalmente desarrollado. [...] Aunque la realidad puede parecer opaca, hay zonas privilegiadas — signos, pistas - que nos permiten penetrarla 6 .

Las breves referencias a $A$ Manhã en la obra de Manuel Bandeira y Cecília Meireles serán tomadas aquí como pistas en un sentido similar. Como tales, ellas dirigen nuestra atención a una fuente importante para el estudio de la literatura brasileña en la década de 1940.

El hecho es que $A$ Manhã fue el órgano oficial del Estado Novo (Estado Nuevo), la dictadura liderada por Getúlio Vargas entre 1937 y 1945 . Este diario tiene mucho que revelar acerca de la obra de los escritores que habían estado vinculados con la renovación modernista en la década de 1920, pero que en la década de 1940 habían ya establecido una reputación y estaban de hecho publicando gran parte de la obra por la cual son recordados hoy ${ }^{7}$. Tomado como una fuente para el estudio de la historia de la literatura, $A$ Manhã trae a la a luz nuevas facetas de escritores como Manuel Bandeira o Cecília Meireles - a quienes tenemos buenas razones para admirar, aunque no conozcamos tan bien como pensábamos - y nos permite una primera mirada al interior de dinámicas más amplias e inesperadas de la vida cultural bajo la dictadura de Getúlio Vargas.

Al perseguir las pistas ofrecidas por las colaboraciones de los autores modernistas a $A$ Manhã, este artículo mostrará que el diario oficial del Estado Novo paradójicamente puso en circulación la obra de escritores de las Américas que eran simpatizantes del Frente Popular. Este esfuerzo de intercambio cultural (intercontinental) encuentra su contexto - y pronto iba a encontrar sus límites también - en el desarrollo de la política exterior del gobierno de Vargas durante la Segunda Guerra Mundial.

otras obras de Ginzburg. Desde la perspectiva de la investigación literaria, es interesante anotar que Ginzburg reconoce la influencia de Leo Spitzer y Erich Auerbach en el desarrollo de su propia aproximación a la investigación histórica. Ver por ejemplo Ginzburg, 1989: vii.

6 Ginzburg, 1989: 123.

7 Por ejemplo, dos de las más conocidas colecciones de poesía de Bandeira fueron publicadas por primera vez en la década de 1940: Lira dos Cinquent'Anos apareció en 1940 y Belo belo en 1948. 


\section{EL DIARIO}

Es bien sabido que el diario mencionado de pasada por Manuel Bandeira y por el editor de Cecília Meireles era el órgano oficial del Estado Novo. La historiadora Angela Maria Castro Gomes lo describe de la siguiente manera:

A Manhã, un diario matutino de Río de Janeiro, comienza a circular en agosto [de 1941] adoptando una postura francamente doctrinaria y explicando didácticamente las ideas del presidente y los logros del régimen ${ }^{8}$.

En 1941, A Manhã era una empresa estatal y se encontraba bajo el control inmediato del gobierno9. Dirigido por el poeta Cassiano Ricardo - quien reporta que el mismo Vargas lo había elegido para el cargo- el diario cumplía en general la función ideológica de explicar, justificar, y homenajear directamente al régimen ${ }^{10}$. Sin embargo, $A$ Manhã tenía sus momentos inesperados. La sección cultural en la cual aparecieron las traducciones de Bandeira, «Pensamento da América», a menudo publicaba excelente material: textos de los mejores autores contemporáneos de las Américas, en traducciones firmadas por distinguidos escritores brasileños tales como Bandeira y Meireles: Esta sección del diario oficial provee una vívida ilustración de la afirmación de Boris Fausto según la cual la dictadura de Vargas adoptó una perspectiva «compleja y contradictoria» en cuanto a la cultura y al arte ${ }^{11}$.

La eficacia y sofisticación de la propaganda de estado bajo la dictadura de Vargas ha sido ampliamente documentada, como también lo ha sido el tratamiento represivo recibido por la prensa ${ }^{12}$. Sea que se hayan enfocado específicamente en la institucionalización de la propaganda o más ampliamente en su significado social, los historiadores han logrado reconstruir una red bien organizada y de largo alcance. Robert Levine anota que el Departamento de

8 Gomes, 1996: 17.

9 Nelson Werneck Sodré especifica que un diario titulado $A$ Manhã había sido publicado antes en Río de Janeiro, entre 1925 y 1929, y fue dirigido primero por Mário Rodrigues y después por Adolfo Porto (Sodré, 1996: 424 y 427). Después de eso, entre mayo y noviembre de 1935, el diario A Manhã de Río de Janeiro, dirigido por Pedro Motta Lima, fue identificado con el (entonces ilegal) Partido Comunista Brasileiro (PCB) y cumplió un papel importante en la agitación opositora de la Aliança Nacional Libertadora (ANL). Este diario fue cerrado por Vargas el 27 de noviembre de 1935, como parte de la represión contra el comunismo (Segatto, 1982: 39).

10 Ver Ricardo, 1970: 78.

11 Fausto, 2006: 121

12 Getúlio Vargas fue presidente de Brasil entre 1930 y 1945 y, de nuevo, entre 1951 y 1954. Los académicos a menudo se refieren al período entero de 1930 a 1954 como la «era Vargas». El Estado Novo corresponde a un período más corto, de 1937 a 1945, cuando Vargas mantuvo directamente poderes dictatoriales. A Manhã fue el diario oficial de la dictadura. 
Imprensa y Propaganda (DIP) llegó a ser «la más importante agencia civil del régimen del Estado Novo» ${ }^{13}$. Daryle Williams destaca los amplios poderes del departamento:

Organizado en cinco divisiones (propaganda, cine y teatro, radio, turismo y prensa), el DIP centralizaba la propaganda, la publicidad y las relaciones públicas de todas las agencias federales y asumía el control de toda la censura estatal de la prensa, el cine, la radio y el teatro ${ }^{14}$.

Maria Helena Capelato concibe de manera amplia el discurso de propaganda y lo analiza a lo largo de la era Vargas. Capelato interpreta el desarrollo general de la propaganda de estado en ese periodo como una estrategia para «reformular los mecanismos de control social»; en particular, ella reconstruye un esfuerzo gubernamental coordinado y en buena parte exitoso por reprimir directamente a los diarios a través de la censura pero también a través de «presión financiera y política» ${ }^{15}$. La publicación de $A$ Manhã como un diario oficial a partir de 1941 encaja en este patrón general ${ }^{16}$.

En sus primeras planas y editoriales, $A$ Manhã le da una importancia abundantemente clara a la propaganda del Estado Novo y al culto a la personalidad del presidente. La primera plana de la primera edición dirigida por Cassiano Ricardo, en 9 de agosto de 1941, muestra una fotografía de Vargas llegando al aeropuerto de Río de Janeiro bajo el encabezado «El retorno del presidente Getúlio Vargas». El 19 de agosto de 1941 Vargas recibe de nuevo un encabezado y una fotografía: «El presidente Getúlio Vargas en el club de golf de Itanhangá». Dos días después encontramos otra foto de Vargas en primera plana, ahora en compañía de unos escolares franceses con el encabezado «El coro de niños [de Croix de Bois] en el Palacio del Catete», y así sucesivamente. Los editoriales del diario son aún más explícitos en perseguir las metas de propaganda del régimen; todos los días, al menos uno de los editoriales de la página 4 recalcaba los logros del Estado Novo. Unos pocos ejemplos bastan para evocar su tono. En la primera edición de $A$ Manhã como diario oficial, 9 de agosto de 1941, un editorial comenta un discurso que Vargas había dado dos días antes en la ciudad occidental de Cuiabá: «Brasil en su totalidad se convierte en una nación debido a la presencia del Jefe de Estado en todas las regiones de su territorio». Al día siguiente, bajo el título «Apoyo para la familia», un editorial observa: «bajo el signo del nuevo régimen, un gran número de familias brasileñas son favorecidas por una protección real, a través de diversas iniciativas

\footnotetext{
13 Levine, 1998: 60.

14 Williams, 2001: 83.

15 Capelato, 1999: 175.

16 Ver Capelato, 1998.
} 
que tienen resultados prácticos y son verdaderamente útiles». Sobre el tema de las relaciones entre los intelectuales y el estado, un editorial publicado el 14 de agosto de 1941 ominosamente declara:

O influxo dado, pelo Ministério da Educação, com auxílios e favores dos mais oportunos às associações culturais, o amparo direto prestado a muitos de nossos escritores, hoje investidos de funções de maior relevo, na esfera da vida pública, e a parte ativa que os centros de atividades intelectuais instalados no país veem tomando em todas as solenidades a que o Estado se associa, comprovam quanto se estreitaram os vínculos que prendem agora o poder público à inteligência nacional.

El ímpetu dado por el Ministerio de Educación por medio de auxilios y favores de lo más oportunos para las asociaciones culturales, el amparo directo prestado a muchos de nuestros escritores, hoy investidos con funciones de mayor relevancia en la esfera de la vida pública, y el papel activo que los centros de actividad intelectual organizados en el país vienen tomando en todas las ceremonias que el estado patrocina, todo ello comprueba cuánto se han estrechado los vínculos que unen el poder público brasileño y la inteligencia nacional.

La meta del estado de controlar la actividad intelectual por medio de auxilios y favores no podría haber sido más claramente formulada. No obstante, una discusión en torno a «Pensamento da América» mostrará que por un breve lapso de tiempo los intelectuales responsables de esta sección cultural tuvieron éxito en poner límites al proyecto represivo del estado.

Entre el 9 de agosto de 1941 y el 8 de enero de 1942 «Pensamento da América» aparecía como una página cultural más o menos semanal incluida en la parte posterior del diario. Durante estos meses era muy independiente y notablemente libre de propaganda. Al mismo tiempo que mantenía una calidad uniformemente alta, revelaba sorprendentes e inconfundibles preferencias por el Frente Popular y por Latinoamérica.

Sin embargo, a partir del 22 de enero de 1942 «Pensamento da América» comenzó a aparecer como un suplemento literario y su línea editorial cambió. El carácter oficial de $A$ Manhã saltó a un primer plano y se afirmó. El suplemento mensual publicado entre 1942 y diciembre de 1944 está más en sintonía con el discurso del Estado Novo y es mucho menos interesante desde el punto de vista literario ${ }^{17}$. El enfoque de este artículo radicará de manera predominan-

17 Ya había completado el manuscrito de este artículo cuando recibí noticia de la publicación de América aracnídea de Ana Luiza Beraba, una bienvenida adición a la bibliografía sobre los intelectuales y el Estado Novo. Beraba discute la sección cultural «Pensamento da América» desde 1941 hasta 1948. Su libro incluye una carta útil con información de autores, traductores y títulos publicados en la sección cultural, así como información fascinante sobre la carrera diplomática de Ribeiro Couto (editor entre 1941 y 1943) y su logro al promover el intercambio cultural al interior de Latinoamérica. Un lector que compare la obra de Beraba y la mía propia notará diferencias de interpretación significativas. Un buen ejemplo está en la eva- 
te en la efímera pero muy estimulante página cultural; incluirá además una breve discusión del suplemento con el fin de revelar los contrastes entre las dos fases de esta sección de $A$ Manhã.

\section{LA PÁGINA CULTURAL}

«Pensamento da América» apareció en el cuerpo de $A$ Manhã diecinueve veces entre el 9 de agosto de 1941 y el 8 de enero de 1942, usualmente los martes o jueves, ocupando por lo general todo el espacio de la página siete o más. La orientación de esta innovadora página cultural le fue encargada al escritor y diplomático Ribeiro Couto. La carrera diplomática proveyó a Ribeiro Couto de amplios y muy valiosos contactos. Él estaba en posición de recurrir a redes internacionales en las cuales las conexiones profesionales coincidían con la amistad y la afinidad política ${ }^{18}$. A pesar de ello, el resultado paradójico de sus simpatías para con el Frente Popular fue que Ribeiro Couto estuvo extraordinariamente aislado en el contexto histórico del Brasil de comienzos de los años 40 .

Mirando hacia atrás a través de setenta años de distancia, el editor de «Pensamento da América» parece tener un gusto impecable y estar muy bien informado. La mayor parte de los escritores contemporáneos cuya obra era publicada en la página - probablemente por primera vez en Brasil- son ahora considerados figuras fundamentales del período: Jorge Luis Borges, Gabriela Mistral, César Vallejo y Alfonsina Storni; Langston Hughes; Pedro Henríquez Ureña y Fernando Ortiz ${ }^{19}$. Generaciones anteriores de intelectuales latinoamericanos recibieron también un espacio significativo en la página y, de nuevo, la obra del editor es impresionante. Unos pocos ejemplos bastan para evocar la amplitud y calidad de la sección cultural: «Pensamento da América» publicó poemas de José Asunción Silva y Rubén Darío (octubre 16 y noviembre 13 de 1941); ficciones de Jorge Isaacs y José Eustasio Rivera (octubre 23 y diciembre 11 de 1941); prosa de Sarmiento y Ricardo Palma (septiembre 16 y diciembre 11 de 1941) y más de una pieza de José Enrique Rodó —una elección

luación del material. Para Beraba, el mejor momento de «Pensamento da América» se da en 1948, durante la permanencia de Renato Almeida como editor; yo sostengo que ésta alcanzó su mayor calidad en el breve período entre agosto de 1941 y el 8 de enero de 1942.

18 Estoy haciendo eco aquí de una observación sobre la coincidencia entre las redes personales y políticas de la izquierda en los años 1930 que le oí a Russell Cobb en la reunión de la American Comparative Literature Association en 2008.

19 Textos de estos autores aparecieron en las siguientes fechas: Borges el 30 de septiembre de 1941, Mistral el 9 de agosto de 1941, Vallejo y Storni el 17 de agosto de 1941, Hughes el 26 de agosto de 1941, Henríquez Ureña el 17 de agosto de 1941, y Ortiz el 4 y 11 de diciembre de 1941. 
extraña para una página que se enfocaba en la cultura de las Américas como un todo, dada la crítica aguda, influyente de Rodó del materialismo norteamericano en su conocido ensayo Ariel. (Los textos de Rodó aparecieron el 16 de octubre de 1941 y el 8 de enero de 1942.)

Justo en la primera edición de $A$ Manhã como diario oficial, un editorial corto pero revelador presentaba la página a los lectores. El texto alude brevemente a la política internacional y procede a definir el proyecto de «Pensamento da América» en términos puramente culturales. Sin embargo, la alusión a la escena internacional es diciente: sugiere que, precisamente a causa del estado indeterminado de los asuntos mundiales, unos pocos intelectuales encontraron espacio en A Manhã para publicar traducciones de la literatura de las Américas. El editorial asegura que «la lección del momento presente» es que hay «una unidad de las Américas». En agosto de 1941, durante las primeras etapas de la Segunda Guerra Mundial, la implicación clara es que las Américas forman una unidad en virtud de su neutralidad. En este respecto, el texto hace eco de la política exterior oficial del gobierno de Vargas en ese momento, la cual enfatizaba la neutralidad del continente ${ }^{20}$.

Sin embargo, en agosto de 1941 la situación de las Américas fue con mucho más inestable de lo que el compromiso con la neutralidad la haría parecer. La neutralidad continental fue, por supuesto, efímera. El ataque a Pearl Harbor que llevó a los Estados Unidos a unirse a la guerra tuvo lugar menos de cuatro meses después, el 7 de diciembre de 1941. Por lo demás, en agosto de 1941 debe haber sido claro para un observador bien informado - o para un diplomático como Ribeiro Couto- que Roosevelt había puesto a los Estados Unidos y a Japón en ruta de choque el verano anterior, cuando detuvo las exportaciones de petróleo a Japón.

Además, el diario mismo dio amplias señales de que las Américas no permanecerían neutrales por mucho tiempo y, más aún, de que Brasil se estaba alineando del lado de los Estados Unidos. El 25 de agosto de 1941 se leía en un titular de primera plana: "“Todos los pueblos son libres de elegir la forma de gobierno bajo la cual quieren vivir". Alianza definitiva entre los Estados Unidos e Inglaterra contra el régimen Nazi». Dos semanas antes, el 13 de agosto de 1941, el diario había impreso en primera plana la foto de un grupo de generales brasileños visitando «la famosa academia militar de West Point».

En medio de esta situación internacional incierta, el compromiso oficial de Brasil con la neutralidad abría la puerta para la publicación de «Pensamento da América». El editor de la página y sus colegas vieron esta oportunidad y fueron tras ella, llevando la página muy discretamente en una dirección anti-fascista.

20 Dulles, 1967: 209. 
Aunque su anti-fascismo fue muy discreto, fue sin embargo muy significativo, porque en las primeras etapas de la Segunda Guerra Mundial corrientes poderosas al interior del Estado Novo favorecían una alianza con la Alemania Nazi ${ }^{21}$.

Después de que el primer editorial de «Pensamento da América» hiciera una referencia de paso a la escena internacional, se esforzó por definir el proyecto de la sección en términos estrictamente culturales:

Para a obra de mútuo conhecimento dos valores intelectuais do continente A Manhã deseja contribuir. Desde a poesia - gênero cuja transposição noutras línguas oferece tantas dificuldades-até a história e a etnografia, passando pela novela e pela crítica, este suplemento publicará trabalhos de autores continentais, cuidadosamente traduzidos por escritores brasileiros ${ }^{22}$.

A Manhã desea contribuir a la obra del mutuo conocimiento de los valores intelectuales del continente. Desde la poesía - género cuya traducción a otras lenguas ofrece tantas dificultades - hasta la historia y la etnografía, pasando por la novela y por la crítica, este suplemento publicará trabajos de autores continentales, cuidadosamente traducidos por escritores brasileños.

Durante los pocos meses de finales de 1941, y hasta el 8 de enero de 1942, «Pensamento da América» hizo cada una de sus restantes apariciones en el terreno demarcado aquí: se enfocó en la literatura del continente y evitó cualquier discusión directa sobre política. El 17 de agosto de 1941 un segundo editorial recalcó insistentemente esta posición: «Nuestra meta es divulgar la literatura, simplemente divulgarla». Y luego, con mayor énfasis aún: «Esta página no es política» ${ }^{23}$.

Sin embargo, a pesar de tal insistencia, una mirada más cercana a la literatura publicada por «Pensamento da América» muestra que una agenda política específica informaba las decisiones editoriales entre agosto de 1941 y enero de 1942. El material publicado no sólo abogaba por la libertad —un tema álgido durante la dictadura de Vargas - sino que muy a menudo era firmado por autores que habían adoptado una posición pública contra el fascismo durante la Guerra Civil española. El panamericanismo de la página cultural era más bien tendencioso, mostrando un claro sesgo hacia Latinoamérica.

21 Boris Fausto describe los desacuerdos sobre la postura de Brasil en la guerra así: entre los «germanófilos» se incluían Filinto Müller, Pedro Aurélio de Góis Monteiro y Eurico Gaspar Dutra (respectivamente, el jefe de la policía de Río de Janeiro, el comandante en jefe del ejército y el ministro de guerra), mientras Oswaldo Aranha, ministro de relaciones exteriores, era la figura más visible del grupo que favorecía una alianza con los Estados Unidos. (Ver Fausto, 2006: 97.)

22 A Manhã, 9 de agosto de 1941: 7.

23 A Manhã, 17 de agosto de 1941: 10. 
Estas opiniones encuentran en una edición de «Pensamento da América» dedicada a Walt Whitman una ilustración emblemática ${ }^{24}$. Aunque el enfoque recae ostensiblemente en el poeta estadounidense, un escritor latinoamericano recibe la mitad del espacio. El muy admirado ensayo de José Martí sobre Whitman, que ha sido influyente en toda Latinoamérica, comparte la página con la poesía de Whitman ${ }^{25}$. Un retrato de Martí aparece a la izquierda y uno de Whitman a la derecha; los dos escritores parecen mirarse el uno al otro a través de la página como iguales. Dos breves fragmentos servirán aquí para ilustrar tanto el tono liberal de «Pensamento da América» como su calidad literaria. En la acertada traducción de Francisco Armond, he aquí la elocuente evocación de Martí de una solidaridad sin fronteras que desestime las jerarquías sociales:

[Whitman] ama os humildes, os derrotados, os répobros, até os malvados. Não desdenha os grandes, mas para ele são grandes apenas os que são úteis. Confraterniza com os carreiros, com os marinheiros, com os lavradores. Caça e pesca com eles e, na época da colheita, viaja com eles no cimo de um carro repleto ${ }^{26}$.

Bajo el retrato de Whitman al lado derecho, leemos la traducción de Tasso da Silveira de «Poets to Come» — otro apasionado llamado a la solidaridad.

Sou um homem que, passando sem nunca se deter, lança um olhar ao acaso sobre

Deixando-vos a missão de prová-lo e defini-lo.

[vós, e depois volta o rosto

Esperando de vós a explicação do sentido profundo de seu ser.

Soy un hombre que, pasando sin detenerse nunca, lanza una mirada al azar sobre

Dejándoos la misión de probarlo y definirlo,

[vosotros, y luego vuelve el rostro

Esperando de vosotros la explicación del sentido profundo de su $\operatorname{ser}^{27}$.

Durante 1941 la calidad del material se mantuvo en este alto nivel, y las tendencias del editor permanecieron intactas. Contrario a lo que podría esperarse, justo mientras «Pensamento da América» fue publicado como una página cultural su espacio se mantuvo libre de propaganda gubernamental ${ }^{28}$.

24 A Manhã, 9 de octubre de 1941: 7.

25 Con respecto al ensayo de Martí sobre Whitman ver Ramos, 2001: 230.

26 [Whitman] ama a los humildes, a los caídos, a los heridos, hasta a los malvados. No desdeña a los grandes, porque para él sólo son grandes los útiles. Echa el brazo por el hombro a los carreros, a los marineros, a los labradores. Caza y pesca con ellos, y en la siega sube con ellos al tope del carro cargado.

27 He aquí el fragmento original de Whitman:

I am a man who, sauntering along without fully stopping, turns a casual look upon you and

Leaving it to you to prove and define it,

[then averts his face,

Expecting the main things from you. (Whitman, 1982: 175).

28 Esta página no imprimió fotos de Getúlio o pasajes de sus discursos. Sólo una vez men- 
El logro del editor es digno de mención. El amplio conocimiento y las extensas conexiones de Ribeiro Couto, así como su buen gusto, son muy notorios durante el primer periodo de «Pensamento da América». Poeta, cuentista y diplomático, Ribeiro Couto sólo ha recibido una moderada atención de parte de los académicos. Más recientemente, Vera Lins ha derivado de una lectura de su poesía una comprensión más matizada del tratamiento de la Modernidad por parte de los escritores brasileños. La larga amistad entre Ribeiro Couto y Manuel Bandeira es discutida en Humildade, Paixão e Morte de Davi Arrigucci y, con mayor detalle, en A Trinca do Curvelo de Elvia Bezerra. Bezerra describe a Ribeiro Couto como un «embajador nato» y destaca su papel al introducir a Manuel Bandeira a su gran círculo de amigos literarios ${ }^{29}$.

Es probable que el editor contara con el consejo de amigos en Hispanoamérica para seleccionar qué piezas publicar. La misma página cultural sugiere los nombres de dos escritores que probablemente influenciaron su línea editorial. Gabriela Mistral y Alfonso Reyes, dos diplomáticos que Ribeiro Couto conocía personalmente muy bien, son una constante presencia durante $1941^{30}$. Mistral se desempeñaba como cónsul de Chile en Brasil en esa época (su ejercicio se extendió entre 1940 y 1945), mientras que Reyes había servido antes como embajador de México, entre 1930 y 1938. Reyes y Mistral no sólo fueron incansables en sus esfuerzos por superar la distancia lingüística y cultural que divide a Brasil de los países hispanohablantes de Latinoamérica, sino que también estaban ambos en términos amistosos con los escritores involucrados en «Pensamento da América».

La larga correspondencia entre Reyes y los brasileños Ribeiro Couto, Manuel Bandeira y Cecília Meireles ha sido agudamente discutida por Regina Aída Crespo, y la de Mistral ha sido examinada por Ana Pizarro. Para Crespo, las cartas de Reyes muestran que «el tema del intercambio cultural era una constante» en su diálogo con Manuel Bandeira y Ribeiro Couto. Más significativamente aún, el embajador mexicano asistía a «una serie de eventos que eran importantes para la comunidad intelectual en Brasil» y contribuyó efecti-

cionó en un encabezado su nombre: «Presidente Vargas, pionero de la compañía naviera México-Brasil» (A Manhã, 30 de octubre de 1941: 7). A pesar del titular, el texto es una entrevista con el embajador de México, quien simplemente resalta los lazos comerciales entre los dos países y anuncia la organización de un instituto para impulsar el intercambio cultural.

29 Bezerra, 1995: 97.

30 La traducción de Ribeiro Couto de «País de ausencia» de Mistral fue publicada justo en la primera edición de la página cultural, el 9 de agosto de 1941, y un artículo de Magdalena Petit sobre su vida y obra apareció el 2 de septiembre de 1941. Además, el nombre de Mistral es mencionado en notas cortas el 26 de agosto y el 11 de diciembre de 1941. Artículos de Alfonso Reyes aparecieron el 11 de noviembre y el 18 de diciembre de 1941. 
vamente a «estimular la discusión de políticas diseñadas para promover una aproximación entre Brasil y los países hispanoamericanos» ${ }^{31}$.

Gabriela Mistral tuvo probablemente una influencia más directa en definir el perfil editorial de «Pensamento da América» simplemente porque ella estaba viviendo en Brasil en esa época, cerca de Río de Janeiro o en la ciudad mis$\mathrm{ma}^{32}$. Ana Pizarro ha reconstruido cuidadosamente este periodo de su vida. $\mathrm{He}$ aquí cómo esta autora describe sus actividades:

[Mistral] se incorpora a la vida literaria del país, informa sobre ella en Chile y en publicaciones extranjeras hacia todo el continente. En dirección contraria en los periódicos nacionales del Brasil informa sobre la producción literaria chilena. Se constituye en un nexo ${ }^{33}$.

Desde nuestro punto de vista, es especialmente útil reproducir el comentario de Pizarro según el cual Manuel Bandeira a menudo le pedía a Mistral información y consejo en asuntos literarios, en particular después de haber aceptado una posición como profesor de Literatura Hispanoamericana en la Faculdade Nacional de Filosofia en $1943^{34}$.

Una red más amplia de afinidad política se superpone a estas conexiones profesionales y personales. Las actividades de Reyes y Mistral en favor de la España Republicana son bien conocidas. Reyes fue una figura clave en el esfuerzo por traer intelectuales españoles exiliados a México cuando la República cayó. Sebastiaan Faber reconstruye su rol como uno de los directores de la Casa de España en Ciudad de México, donde los refugiados eran alojados y donde trabajaron entre 1938 y 1940, y su contribución, más tarde, al desarrollo del Colegio de México ${ }^{35}$. Por su parte, Mistral donó las ganancias de una colección de poesía publicada en 1938, Tala, a los huérfanos de la Guerra Civil española —a «los niños vascos refugiados en la Residencia de Pedralbes, Barcelona», como ella misma lo puso en una carta a su editora, Victoria Ocampo ${ }^{36}$. Las simpatías de Mistral para con el Frente Popular se extendían más allá de la España Republicana. Ella fue durante mucho tiempo partidaria y amiga personal de Pedro

31 Crespo, 2003: 200.

32 Con respecto al americanismo de Gabriela Mistral, ver los enfoques ligeramente diferentes de Jaime Concha y Jonathan Cohen.

33 Pizarro, 2005: 1978.

34 Ver también la cronología en Bandeira, 1958, 1: CVI.

35 Faber, 2002: 18-19.

36 Horan, 2033: 48. La fecha de la carta de Mistral, 4 de agosto de 1937, hace esta frase aún más significativa. Mistral escribió a Ocampo menos de dos meses después de que las Fuerzas Nacionalistas tomaron control del País Vasco en junio de 1937; además de eso, a lo largo del año en que Tala fue publicado Barcelona sufrió bombardeos de los nacionalistas y sus aliados. 
Aguirre Cerda, quien fuera elegido presidente de Chile en 1938, representando a una plataforma del Frente Popular ${ }^{37}$.

Las decisiones de Ribeiro Couto como editor de «Pensamento da América» son consistentes con las simpatías políticas de Mistral y Reyes. Durante 1941 le dio considerable espacio a escritores latinoamericanos y norteamericanos que habían adoptado una posición pública en favor de la España Republicana. Un patrón interesante es que la obra de escritores que habían sido delegados en el Segundo Congreso Internacional para la Defensa de la Cultura aparece en la página muy a menudo. Este Congreso, que tuvo lugar en 1937 en España y París y sirvió como un foro de intelectuales partidarios de la República, es descrito por el historiador Robert S. Thornberry como «una importante victoria moral para el gobierno republicano» ${ }^{38}$. He aquí algunos de los delegados cuya obra aparece en la página: de Latinoamérica Pablo Neruda, César Vallejo y Vicente Huidobro, y de los Estados Unidos Langston Hughes y Waldo Frank ${ }^{39}$. Sabemos bien que, además de tomar parte en el Congreso, muchos de estos escritores abordaron en su obra el tema de la Guerra Civil española. Por ejemplo, «España, aparta de mí este cáliz» de Vallejo ya estaba disponible en imprenta en 1940, y Ribeiro Couto pudo haber sido consciente de eso.

Otro patrón interesante tiene que ver con los autores norteamericanos. En 1941 «Pensamento da América» otorga mucho menos espacio a los escritores norteamericanos que a los latinoamericanos, pero los pocos escritores de los Estados Unidos cuya obra se publica son por regla general voces opositoras al fascismo. La primera edición de la página cultural sirve para ilustrar ambos puntos. El 9 de agosto de 1941 se dedicaron más de dos páginas a siete columnas a textos de escritores latinoamericanos o a artículos que discutían el arte y la literatura de Latinoamérica ${ }^{40}$. En la esquina inferior izquierda de la primera página encontramos dos poemas cortos de Archibald McLeish traducidos por Manuel Bandeira. McLeish era un prominente intelectual con simpatías de izquierda. Michael Denning, en su detallada e iluminadora reconstrucción de la cultura del Frente Popular en los Estados Unidos, llama la atención sobre las piezas de contenido social con las que McLeish contribuyó a Fortune durante la década de

37 James E. Irby me sugirió considerar el Frente Popular como contexto de la carrera de Gabriela Mistral, hace años, en una conversación.

38 Thornberry, 2000: 590. Manuel Aznar Soler y Mario Schneider han dedicado tres volúmenes a la discusión y documentación del Segundo Congreso Internacional. Ver también: Escolar 117 y 121.

39 Estos autores fueron publicados respectivamente el 13 de noviembre de 1941, el 18 de diciembre de 1941, el 17 de agosto de 1941, el 26 de agosto de 1941 y el 6 de noviembre de 1941.

40 A Manhã, 9 de agosto de 1941: 17-18. 
1930, y además lo presenta como una figura clave en la creación del género del «radio teatro serio» (cuyo más memorable ejemplo es «La guerra de los mundos» de Orson Welles). Los propios dramas antifascistas de McLeish, The Fall of the City y Air Raid, fueron transmitidos por CBS en 1937 y 1938 y alcanzaron un significativo «éxito entre el público y la crítica» ${ }^{41}$. Es revelador que los pocos escritores norteamericanos que «Pensamento da América» publicó reciben todos un papel en la reconstrucción que Denning hace de la cultura de la izquierda estadounidense: además de los escritores ya mencionados —McLeish, Langston Hughes y Waldo Frank - también está William Saroyan ${ }^{42}$.

En el contexto histórico de la dictadura de Vargas, es una sorpresa encontrar tanta simpatía por el Frente Popular expresada en un foro público, ni qué decir en este foro público en particular. Dos años antes de que se estableciera el Estado Novo, cuando Vargas cumplía un periodo como presidente electo, este propinó dos duros golpes a la izquierda opositora. A principios de 1935 se organizó a nivel nacional un amplio frente político, la Aliança Nacional Libertadora (ANL). Antes de que Vargas la cerrara en julio del mismo año, la ANL emprendió una intensa actividad política a muchos niveles, incluyendo la campaña anti-fascista. En opinión del historiador Paulo Sérgio Pinheiro, aunque la ANL mobilizó grandes sectores de la población a lo largo de todo el país, reclutando trabajadores y obreros, su liderazgo permaneció «en manos de sectores de las clases media y media-alta ${ }^{43}$. Al mismo tiempo que el programa de la ANL tenía mucho en común con los programas generales de otros frentes populares de la época, el (entonces ilegal) Partido Comunista Brasileño (PCB) jugó un papel clave en su organización ${ }^{44}$. Los meses que siguieron inmediatamente después de que el gobierno de Vargas cerró la ANL vieron incrementada la represión política. Todavía el 27 de noviembre de 1935, los comunistas buscaban tomarse el poder en Brasil por medio de una insurrección militar. Este movimiento tuvo

41 Denning, 1997: 383-90. Ver también Buitenhuis, 1996.

42 Una traducción de «The Daring Young Man on the Flying Trapeze» de William Saroyan por R. Magalhães Júnior fue publicada el 17 de agosto de 1941. Los otros escritores norteamericanos publicados por «Pensamento da América» en 1941 fueron Whitman (2 de septiembre de 1941, 9 de octubre de 1941) y Aline Kilmer (27 de noviembre de 1941). Sobre la recepción de Whitman en Brasil ver las discusiones de Charles Perrone y Maria Clara Bonetti Paro.

43 Pinheiro, 1991: 274. He aquí el resumen de Paulo Sérgio Pinheiro de las actividades de la ANL: «En São Paulo, células de la ANL denunciaban las precarias condiciones de trabajo y defendían un salario mínimo para los obreros; en el noreste, la ANL atacaba la corrupción del gobierno y la explotación de los trabajadores rurales, mientras en Río de Janeiro el énfasis se ponía en las libertades civiles.»

44 Para discusiones acerca de la ANL ver también: Motta, 2002: 180, 273-4 y Dulles, 1967: 147. 
corta vida y fue violentamente reprimido 45 . En este contexto, es muy sorprendente encontrar que la dictadura de Vargas, habiendo llegado al poder como resultado de una doble derrota de la izquierda, hubiera dedicado una o más páginas de su diario oficial a la cultura del Frente Popular.

«Pensamento da América» estaba aislada en más de una forma. No sólo era una página adepta al Frente Popular impresa en un diario comprometido con propaganda de la dictadura; muchos intelectuales de izquierda evitaban $A$ Manhã, especialmente aquellos que gravitaban en torno al Partido Comunista ${ }^{46}$. Es verdad que, a pesar del carácter represivo de la dictadura de Vargas, había muchos intelectuales que mantenían simpatías con la izquierda aun cuando encontraban empleo en la administración, o que ocasionalmente colaboraban en publicaciones del Departamento de Imprensa e Propaganda ${ }^{47}$. Un caso muy conocido es el del gran poeta Carlos Drummond de Andrade, quien fue un funcionario de alto rango en el Ministério da Educaçao entre 1934 y 1945, y nunca mantuvo en secreto su simpatía por la Unión Soviética ${ }^{48}$. Drummond conservó distancia de $A$ Manhã. Aunque era colaborador ocasional de un suplemento del diario dedicado a la literatura brasileña, Drummond no contribuyó a «Pensamento da América» ni parece haber publicado en el diario mismo ${ }^{49}$.

El aislamiento de Ribeiro Couto y sus colegas es manifiesto también desde otras perspectivas. A juzgar por las opiniones expresadas por Manuel Bandei-

45 Pinheiro discute la coincidencia inesperada de que en 1935, cuando la Internacional Comunista adoptó oficialmente una estrategia de frente popular, el Partido Comunista Brasileño intentó tomarse el poder del país por medios militares. Ver Pinheiro, 1991: 308-331.

46 Como lo recuerda Moacir Werneck de Castro en una entrevista personal.

47 Fausto, 2006: 117.

48 Schwartzman, Bomeny y Ribeiro Costa anotan que, a pesar de los frecuentes conflictos entre Gustavo Capanema, el ministro de educación, y Carlos Drummond de Andrade, los dos tienen, juntos, «enorme responsabilidad en las trayectorias contradictorias, a veces fecundas y frecuentemente desconcertantes, que adoptaron la educación y la cultura en Brasil» durante los años de Vargas (Schwartzman, 1984: 84). Para una discusión de la participación de los intelectuales en el Ministério de la Educação, ver también Castro, capítulo 2. En 1945, Drummond participó brevemente en el consejo editorial de una publicación comunista, la Tribuna popular (Segatto, 1982: 77). Sin embargo, poco después rompió con el partido. Vagner Camilo discute la desilusión de Drummond con el comunismo y reconstruye cuidadosamente los ataques que el poeta recibió de parte del partido después de que lo dejó (Camilo, 2001: 63-88).

49 Tuve la oportunidad, en otro contexto, de discutir las contribuciones de Drummond a «Autores e Livros», un suplemento de $A$ Manhã dedicado a la literatura y la cultura brasileñas. En el curso de tres años y medio, Drummond publicó solamente trece poemas en «Autores e Livros», que parece haber gozado de una aceptación más amplia que el diario. Recordando esos años durante una entrevista en 1995, Moacir Werneck de Castro, quien se identificaba a sí mismo como comunista, dijo que él no habría contribuido a $A$ Manhã porque era el órgano del Estado Novo, pero admitió que leía «Autores e Livros» porque «todo el mundo lo leía». 
ra, los intelectuales involucrados en «Pensamento da América» eran hostiles al comunismo. En Itinerário de Pasárgada (1954), el poeta usa palabras fuertes en un comentario sobre el compromiso político de su amigo personal Paul Éluard, a quien había conocido en Suiza en 1913: «Confío en que su talento poético, muy personal y aristocrático (toda su obra lo atestigua), nunca sucumbirá a la estética grosera impuesta por el comunismo ruso a sus esclavos $\rangle^{50}$. En otro pasaje, Bandeira se refiere a un rumor que tergiversa sus acciones como «uno de esos sórdidos asuntos» en los que los comunistas sobresalen ${ }^{51}$.

Una reacción más matizada al comunismo se registra en un poema muy conocido de Bandeira, «O Martelo» («El martillo»). Cuando el hablante describe el estruendo hecho por el martillo de un herrero, su tono logra combinar la exasperación y la ironía con la gratitud. He aquí el texto completo del poema:

As rodas rangem na curva dos trilhos

Inexoravelmente.

Mas eu salvei do meu naufrágio

Os elementos mais cotidianos.

O meu quarto resume o passado em todas as casas que habitei.

Dentro da noite

No cerne duro da cidade

Me sinto protegido.

Do jardim do convento

Vem o pio da coruja.

Doce como um arrulho de pomba.

Sei que amanhã quando acordar

Ouvirei o martelo do ferreiro

Bater corajoso o seu cântico de certezas ${ }^{52}$.

50 Bandeira, 1958, 2: 41.

51 Bandeira, 1958, 2: 69.

52 Las ruedas rechinan en la curva de los rieles.

Implacablemente.

Pero yo salvé de mi naufragio

Los elementos más cotidianos.

Mi cuarto resume el pasado de todas las casas que habité.

En la noche

En el duro corazón de la ciudad

Me siento protegido.

Desde el jardín del convento

Viene el trinar de la coruja.

Dulce como arrullo de paloma.

Sé que mañana cuando despierte

Oiré el martillo del herrero

Golpear animoso su canción de certidumbres.

(Versión en español de José Javier Villareal.) 
El poema está organizado alrededor de una secuencia de sonidos: el rechinar del tranvía, el chirrido de la lechuza y el arrullo de las palomas y, finalmente, el valeroso cântico de certezas del martillo. Aunque los estridentes sonidos de la ciudad enmarcan los pacíficos sonidos de los pájaros, el tono del poema se vuelve más esperanzado conforme se desarrolla. Hacia el final, el poeta encuentra algún consuelo en el valeroso ruido del martillo aunque él no comparta sus certezas. El autor parece contento de concluir su lista de cosas diarias rescatadas con esta alusión al comunismo ${ }^{53}$.

Si comparamos la situación de los intelectuales responsables de «Pensamento da América» con la de los escritores que publicaban, podremos ver aún desde otra perspectiva su aislamiento. Durante la dictadura de Vargas, Ribeiro Couto y sus colegas no podían expresar abiertamente su simpatía por el Frente Popular. En contraste, cuando Alfonso Reyes llevó a México a los exiliados de la España Republicana después de la Guerra Civil contaba con el apoyo del gobierno de Cárdenas ${ }^{54}$. Gabriela Mistral, por su parte, había estado conectada con Pedro Aguirre Cerda mucho antes de que fuera elegido presidente de Chile.

Ribeiro Couto y sus colegas no sólo estaban por fuera de los círculos del poder político real en Brasil, estaban socialmente aislados también. El trabajo de Michael Denning sobre la cultura del Frente Popular en los Estados Unidos pone de relieve este aspecto de manera aguda. Denning llama la atención sobre la «incómoda, pero poderosa» alianza de tres importantes grupos que se definían por su afiliación social y estética: los escritores «modernos», bien establecidos, que usualmente tenían una educación de elite y fueron atraídos por la izquierda; los "émigres», europeos que habían huido del fascismo y a menudo tenían un bagaje marxista; y los «plebeyos», niños que constituían la «segunda generación de la segunda hola de inmigración» y que se educaron en bibliotecas y escuelas públicas ${ }^{55}$. Buscaríamos en vano un consenso amplio de la izquierda en Brasil durante el Estado Novo, y sería ciertamente inconducente buscar analogías brasileñas de los grupos que Denning describe. Sin embargo, una de las categorías propuestas por este historiador puede describir adecuadamente a los intelectuales de «Pensamento da América»: Ribeiro Couto y Manuel Bandeira son, en términos de Denning, «modernos». Ambos pertenecían

53 Estoy en deuda con la sensible discusión de Davi Arrigucci sobre «O Martelo» en «O Humilde Cotidiano de Manuel Bandeira». La lectura de Nicolau Sevcenko de la poesía de Manuel Bandeira como un contrapunto crítico a los discursos modernizantes en Brasil parece consistente con la interpretación de Arrigucci.

54 Faber, 2002: 18.

55 Denning, 1997: 58-61. 
a una elite educada. Ya en 1941, Ribeiro Couto había escrito catorce colecciones de poesía, cuentos y crónicas, y había sido miembro de la Academia Brasileira de Letras (ABL) desde 1934. A principios de la década de 1940, Manuel Bandeira ya era considerado uno de los más grandes poetas del país; también había sido recientemente elegido para la Academia ${ }^{56}$. Entonces, a pesar de sus simpatías con el Frente Popular, para los intelectuales de «Pensamento da América» la «literatura» seguía siendo un trabajo de la elite a la cual pertenecían. En consecuencia, su página estaba dirigida a una audiencia letrada sofisticada y restringida.

Otro contraste entre el frentepopulismo de «Pensamento da América» y el del frente cultural norteamericano sale a la superficie aquí. En los Estados Unidos, este movimiento tuvo repercusiones grandes y duraderas. En palabras de Denning,

[El Frente Popular] dejó su huella en las instituciones de la cultura estadounidense — desde la radiodifusión y Hollywood a la novela y las universidades - e influenció a aquellos que crecieron en las clases subalternas de la sociedad de los Estados Unidos ${ }^{57}$.

En contraste, el trabajo solitario de Ribeiro Couto y sus colegas en «Pensamento da América» no ha tenido mayores repercusiones.

Aún así, Ribeiro Couto tiene en su haber un impresionante logro como editor de «Pensamento da América». Él creó y mantuvo una página cultural de gran calidad y la conservó libre de propaganda aun dentro del diario oficial del Estado Novo; durante una época en la que el público brasileño tenía poco contacto con la literatura hispanoamericana, él logró poner a disposición del público buenas traducciones $\mathrm{y}$, finalmente, le dio espacio a obras literarias que no encajaban con facilidad en los límites que el gobierno represivo buscaba imponer a la vida intelectual. Además de esto, aunque los intelectuales de «Pensamento da América» estaban aislados, ellos encontraron maneras creativas de resistir a la ofensiva propagandística del Estado Novo. Desde agosto de 1941 hasta comienzos de enero de 1942 - mientras la postura de Brasil y las Américas vis-à-vis la guerra en Europa permanecía indeterminada - Ribeiro Couto y sus colegas lograron abrir un espacio a los escritores frentepopulistas aun dentro del diario oficial del régimen. Pero la situación de Brasil cambió después de enero de 1942, y cambió

56 Bandeira cuenta su elección a la Academia en 1940 en Itinerário de Pasárgada (Bandeira, 1958, 2: 91-94.) Los patrocinadores de su candidatura fueron Ribeiro Couto, Cassiano Ricardo y Múcio Leão (editor de «Autores e Livros», otro suplemento de $A$ Manhã).

57 Denning, 1997: 38. 
también el contexto en el que trabajaban. Al mismo tiempo en que el año nuevo atestiguaba el nacimiento de una alianza entre Brasil y los Estados Unidos, llegó el fin para el aislamiento y la independencia de «Pensamento da América».

\section{EL SUPLEMENTO}

La primera edición de «Pensamento da América» como suplemento dominical apareció el 22 de enero de 1942 con una línea editorial muy cambiada. Expandida significativamente, la sección cultural ahora comienza a aparecer una vez al mes en un suplemento que por momentos llegaba a tener hasta 32 páginas. Sin embargo, si lo comparamos con la página cultural de 1941, el suplemento parece desenfocado y su contenido desleído y predecible. «Pensamento da América» ahora se mezcla de manera bastante natural con el discurso de propaganda de $A$ Manhã. No obstante, parece identificarse especialmente con la posición de Oswaldo Aranha, el ministro de relaciones exteriores, que era reconocido como liberal por sus contemporáneos. En medio de un contexto internacional enrarecido, el apoyo de Brasil a los Estados Unidos durante la guerra sale a la luz y pone la pauta de la sección cultural. Ribeiro Couto permanece como editor hasta el 28 de marzo de 1943, y desde ese momento Renato Almeida ocupa esta posición. Manuel Bandeira continúa colaborando con el suplemento, pero cada vez con menos frecuencia después de 1942; de otra parte, las traducciones de Cecília Meireles comienzan a aparecer con mucha mayor frecuencia en los años posteriores.

Es significativo que el cambio de formato de «Pensamento da América» coincide con la Tercera Reunión de Ministros de Asuntos Exteriores de las Américas, que tuvo lugar en Río de Janeiro entre el 15 y el 28 de enero de 1942, y que fue clave en el desarrollo de las políticas de guerra en los países del continente americano. La edición de enero del suplemento apareció durante la reunión y trató de ella, mientras la edición de febrero reprodujo el texto completo del discurso de Oswaldo Aranha en la ceremonia de clausura. Ya que esta reunión ocupó los titulares de A Manhã durante casi todo un mes, desde el 9 hasta el 30 de enero de 1942, el espacio prominente que «Pensamento da América» le dedica al evento lo hace parecer una continuación del diario.

Según el historiador John F. Dulles, la meta de los Estados Unidos en la reunión de Río era lograr que todas las naciones del continente rompieran relaciones diplomáticas con el Eje. Los ministros sólo aceptaron una recomendación de ruptura pero, con excepción de Chile y Argentina, la mayor parte de 
los países eligieron tomar este curso de acción ${ }^{58}$. Más recientemente, el historiador Stanley Hilton ha reconstruido la contribución de Aranha a esta reunión. Partidario desde hacía mucho tiempo del alineamiento de Brasil con los Estados Unidos, Aranha estaba comprometido sin embargo con la búsqueda de unos términos para la resolución final que fueran aceptables para Argentina y Chile ${ }^{59}$. El mismo Aranha anunció el rompimiento de Brasil con las naciones del Eje en el discurso que dio el último día de la reunión - el mismo discurso que fue reproducido luego en su totalidad en la edición de febrero de «Pensamento da América».

La primera plana de la edición de enero de 1942 del suplemento es reveladora. Un editorial explicando el nuevo formato ocupa la mitad superior de las tres columnas centrales, mientras una gran foto de Getúlio Vargas y Roosevelt, juntos, llena la mitad inferior de este espacio. El editorial y las fotografías están flanqueadas, en la izquierda, por un texto breve y poco claro de Vargas sobre la posición del gobierno brasileño vis-à-vis el conflicto internacional. Un artículo de Cassiano Ricardo llena la última columna de la página. Comienza retratando a Vargas como el «hombre providencial» que está construyendo «un camino seguro para su pueblo» en un momento difícil, y luego emprende un elogio del Estado Novo. Esta disposición sugiere que el suplemento abordaría la cultura de las Américas desde la perspectiva del alineamiento de Brasil con los Estados Unidos, que pronto habría de ser anunciado. Además, el título del artículo de Cassiano Ricardo - $« \mathrm{O}$ Estado Novo e o Panamericanismo»- no deja duda de que, a partir de ese momento, la sección cultural ya no se mantendría libre de política o propaganda.

En contraste con el texto que había introducido la página cultural en agosto de 1941, el corto editorial de enero de 1942, «Explicação deste suplemento», dedica la mayor parte del espacio a describir el «momento dramático» en la historia de las Américas. Justifica el cambio en la línea editorial refiriéndose a la «solidaridad integral» que los tiempos requerían para el continente. Formula claramente una nueva dirección: «Pensamento da América», que hasta el momento «había mantenido un carácter meramente literario y artístico», comenzaría a «adoptar un caráter político también» ${ }^{60}$.

58 Dulles, 1967: 221-225.

59 Hilton, 1994: 338.

60 Debo anotar la divergencia entre mi interpretación de la editorial del 22 de enero de 1942 y la de Beraba. Mientras yo considero que documenta un momento de cambio decisivo, el momento en el que el discurso oficial del Estado Novo se impuso sobre la sección cultural, Beraba ve el mismo texto como si marcara una victoria para los intelectuales que habían estado defendiendo un panamericanismo antiimperialista y lograron asegurar más espacio en el diario 
El efecto acumulativo de los cambios editoriales es que «Pensamento da América» pierde su orientación literaria y política y que su calidad se vuelve irregular. Las obras no literarias que comienza a publicar son todo menos interesantes. El suplemento ahora incluye largos artículos didácticos describiendo «la geografía y la historia» de cada país junto con biografías de eminentes líderes políticos. Estos nuevos rasgos revelan además un distanciamiento del anterior sesgo en favor de Latinoamérica. A manera de ilustración, la edición de enero de 1942 dedicó más de seis de sus treinta y dos páginas a un artículo sobre los Estados Unidos y dos páginas a una biografía de George Washington, pero incluyó hacia el final un artículo de tres páginas sobre Venezuela y una biografía de Simón Bolívar de una página.

Es verdad que después de 1942 «Pensamento da América» continúa publicando el material literario que había hecho tan interesante la anterior página cultural. Sin embargo, ahora comienza a relegar a espacios marginales las traducciones literarias y la obra de escritores frentepopulistas, con la consecuencia de que su calidad general se ve afectada. El 22 de febrero de 1942, por ejemplo, el suplemento publicó una obra en prosa sin mayor interés acerca de las relaciones de raza en Brasil firmada por Theodore Roosevelt ${ }^{61}$. No sólo habría difícilmente aparecido en la página cultural de 1941; esta pieza desvirtúa una traducción de Whitman incluida en la siguiente página. Otra práctica adicional debilitó el suplemento. «Pensamento da América» adoptó la costumbre de republicar textos que ya habían aparecido en 1941. La edición de enero de

para su perspectiva. Beraba atribuye además a Manuel Bandeira la autoría de este editorial (que está sin firmar, como es usualmente el caso en $A$ Manhã). Para apoyar esta opinión, ella se refiere a un editorial posterior, que parece ser el de la edición fechada 22 de marzo de 1942. Aquí está el pasaje relevante de este documento: «En los primeros días de octubre de 1941, el encargado de esta sección [Ribeiro Couto] tuvo que ausentarse en un viaje por el extranjero, viaje del que sólo regresó ahora, en marzo de 1942. En su ausencia, se encargó de la dirección de "Pensamento da América" el ilustre redactor de la sección de Artes Plásticas de A Manhã, Manuel Bandeira. Y los tres -Manuel Bandeira, Múcio Leão [director del suplemento "Autores e Livros"] y Cassiano Ricardo [director del diario] — decidieron, con la más justa razón, uniformizar los dos suplementos ["Autores e Livros" e "Pensamento da América"]. A partir del pasado 22 de enero, "Pensamento da América" comenzó a publicarse una vez por mes, con el formato de “Autores e Livros”» («Pensamento da América», 22 de marzo de 1942: 58). Más bien que establecer que Manuel Bandeira fue el autor del editorial del 22 de enero, este pasaje muestra que la decisión de hacer cambios en «Pensamento da América» fue tomada en ausencia de Ribeiro Couto por un grupo de tres personas, entre los cuales Bandeira tenía el menor poder en el diario. Además, sobre la base de la evidencia textual es difícil aceptar que Bandeira pudo haber escrito un editorial desdeñando el «carácter meramente literario y cultural» de «Pensamento da América».

61 «Pensamento da América», 22 de febrero de 1942: 41. 
1942 publicó sólo tres traducciones nuevas, pero reimprimió muchas más. Al final, casi un cuarto del suplemento de 32 páginas fue llenado con material que ya había aparecido en la página cultural de $1941^{62}$.

\section{PISTAS A LA HEGEMONÍA}

Si miramos la interesante e independiente página cultural publicada en 1941 desde la perspectiva del predecible suplemento oficial que apareció a partir de 1942, parece claro que Ribeiro Couto y sus colegas se aprovecharon de una rara - y fugaz - convergencia de intereses políticos con el fin de abrir una brecha en el discurso de propaganda del Estado Novo y poner en circulación la obra de los escritores frentepopulistas. Por pocos meses, mientras la posición de Brasil en la guerra aún estaba siendo discutida al interior del gobierno de Vargas, las simpatías antifascistas de los intelectuales de «Pensamento da América» podían ir de la mano de la oposición a Alemania de Oswaldo Aranha. Es como si durante 1941 «Pensamento da América» estuviera volando bajo el espectro del radar, cumpliendo una función no todavía oficial, de tal manera que dejó a su editor con la libertad de definir el contenido político y literario de la página. Aun cuando estaba volcado hacia el Frente Popular latinoamericano, el panamericanismo de Ribeiro Couto cumplió el papel durante este breve periodo de apoyar la posición de Oswaldo Aranha.

Todo cambió en el momento en que la perspectiva de Oswaldo Aranha emergió victoriosa y Brasil se alineó con los Estados Unidos. El panamericanismo de «Pensamento da América» fue absorbido al interior del discurso oficial del Estado Novo y se vio alterado por este contexto nuevo y abrumador. El suplemento editado por Ribeiro Couto perdió sus elementos más interesantes y distintivos; eventualmente, perdió también a su editor.

Sin embargo, la narrativa del rol de esta sección cultural, desde la perspectiva de las luchas internas del Estado Novo acerca de la política de guerra, no puede ser sino unilateral. Los intelectuales responsables de dar forma a «Pensamento da América» sin duda preferirían poner el énfasis en los pocos meses de finales de 1941 durante los cuales lograron resistir al control de la dictadura y de paso crearon una sección cultural extraordinaria.

62 Esta edición reimprime traducciones de los siguientes escritores: Patricia Morgan (por Manuel Bandeira), Alfonsina Storni (por Ribeiro Couto), Waldo Frank (por Vinicius de Morais), César Vallejo y Sarmiento. 
Al seguir las pistas ofrecidas por las referencias de paso al diario $A$ Manhã en los libros de Manuel Bandeira y Cecília Meireles, la presente discusión en torno a «Pensamento da América» ha traído a la luz algunos de los complejos movimientos por medio de los cuales se constituyó, disputó y reconstituyó la hegemonía cultural y política en el contexto histórico del Brasil de principios de la década de 1940. La trayectoria de «Pensamento da América» como página cultural y como suplemento toma forma a través de un proceso de toma y dame que involucró a intelectuales y otros actores con proyectos políticos diversos, a veces superpuestos, pero con mayor frecuencia divergentes. Al mismo tiempo que Ribeiro Couto y sus colegas ayudaron a formar el discurso de legitimación del Estado Novo en $A$ Manhã, su actividad no se circunscribía a estos límites, sino que se resistía a ellos. A la inversa, aun cuando perseguía calladamente una agenda antifascista, «Pensamento da América» parecía prestar distinción intelectual a la propaganda de la dictadura de Vargas por medio de su sola presencia en el diario oficial.

Las reflexiones de Gramsci sobre la hegemonía ofrecen una perspectiva útil para comprender las ambigüedades de «Pensamento da América», en parte quizá porque el mismo Gramsci es casi contemporáneo de estos intelectuales (y confrontó también al fascismo, pero mucho más directamente de lo que ellos lo hicieron). El complejo proceso por medio del cual se constituyó un consenso social durante el Estado Novo provee el horizonte para la actividad de Ribeiro Couto y sus colegas, pero no la agota. En su esfuerzo por resistir la ofensiva represiva de la dictadura, estos intelectuales se comprometieron con un tipo de periodismo en el que lo político se superpone a lo cultural: al mismo tiempo que contribuyeron a alejar a Brasil del Eje, Ribeiro Couto y sus colegas crearon una sección de gran calidad que puede ser leída con placer aún hoy ${ }^{63}$. Hay muchas sorpresas gratificantes esperando por aquellos que leen «Pensamento da América» hoy. Parece oportuno anotar, a manera de conclusión, que una traducción de «Entrada a la madera» de Pablo Neruda fue publicada por la página cultural el 18 de diciembre de 1941. Esta obra conjunta estaba firmada por Manuel Bandeira y Dante Milano, pero no fue incluida en los Poemas traduzidos de Bandeira.

63 La a menudo citada definición del estado como «hegemonía protegida por la armadura de la coerción» se encuentra en Gramsci, 2007, III: 73. El volumen Selections from the Prison Notebooks incluye dos influyentes pasajes sobre los intelectuales en el estado moderno (Gramsci, 1971: 5-23). En la vasta bibliografía sobre Gramsci, he encontrado particularmente útil la cuidadosa discusión de sus argumentos por Vacca y Showstack Sassoon. 


\section{BIBLIOGRAFÍA}

A Manhã (1941-1945), Biblioteca Nacional, Rio de Janeiro.

Arrigucci Jr., Davi, Enigma e comentário, São Paulo, Companhia das Letras, 1987.

Arrigucci Jr., Davi, Humildade, Paixão e Morte, São Paulo, Companhia das Letras, 1990.

Aznar Soler, Manuel y Schneider, Luis Mario, II Congreso Internacional de Escritores Antifascistas (1937), Barcelona, Editorial Laia, 1979, 3 volúmenes.

Bandeira, Manuel, Poesia e prosa, Rio de Janeiro, Editora José Aguilar, 1958, 2 volúmenes.

Bezerra, Elvia, A trinca do Curvelo, Rio de Janeiro, Topbooks, 1995.

Buitenhuis, Peter, «Prelude to War: The Interventionist Propaganda of Archibald McLeish, Robert E, Sherwood, and John Steinbeck», Canadian Review of American Studies (versión electrónica) 26/1 (Winter 1996).

Camilo, Vagner, Drummond, São Paulo, Ateliê Editorial, 2001.

Capelato, Maria Helena, Multidões em cena, São Paulo/ Campinas, FAPESP/Papirus, 1998.

Capelato, Maria Helena, «Propaganda política e controle dos meios de comunicação», Dulce Pandolfi (ed.), Repensando o Estado Novo, Rio de Janeiro, Editora Fundação Getúlio Vargas, 1999: 167-178.

Castro, Moacir Werneck de, entrevista, 21 marzo 1995.

Castro, Moacir Werneck de, Mario de Andrade. Rio de Janeiro, Rocco, 1989.

Cohen, Jonathan, «Toward a Common Destiny on the American Continent», Marjorie Agosín (ed.), Gabriela Mistral, Athens, Ohio, Ohio University Press, 2003: $1-18$.

Concha, Jaime, Gabriela Mistral, Madrid, Edicciones Júcar, 1987.

Crespo, Regina Aída, «Cultura e política», Revista Brasileira de História, 23/45 (julio 2003): 187-208.

Denning, Michael, The Cultural Front, London, Verso, 1997.

Dulles, John W. F., Vargas of Brazil, Austin, University of Texas Press, 1967.

Escolar, Hipólito, La cultura durante la guerra civil, Madrid, Editorial Alhambra, 1987.

Faber, Sebastiaan, Exile and Cultural Hegemony, Nashville, Tennessee, Vanderbilt University Press, 2002. 
Faber, Sebastiaan, «La hora ha llegado», en Ideologies of Hispanism, Nashville, Tennessee, Vanderbilt University Press, 2005: 62-104.

Fausto, Boris, Getúlio Vargas, São Paulo, Companhia das Letras, 2006.

Ginzburg, Carlo, The Cheese and the Worms, New York, Penguin, 1982.

Ginzburg, Carlo, Clues, Myths, and the Historical Method, Baltimore, Johns Hopkins University Press, 1989.

Ginzburg, Carlo, «Microhistory», Critical Inquiry, 20/1 (Autumn 1993): 10-35.

Gomes, Angela de Castro, História e historiadores, Rio de Janeiro, Fundação Getúlio Vargas Editora, 1996.

Gramsci, Antonio, Prison Notebooks, New York, Columbia University Press, 2007.

Gramsci, Antonio, Selections from the Prison Notebooks, New York, International Publishers, 1971.

Hilton, Stanley, Oswaldo Aranha, Rio de Janeiro, Editora Objetiva, 1994.

Horan, Elizabeth y Doris Meyer (eds.), This America or Ours (The Letters of Gabriela Mistral and Victoria Ocampo), Austin, University of Texas Press, 2003.

Levine, Robert M., Father of the Poor?, Cambridge, Cambridge University Press, 1998.

Lima, Henrique Espada, A Micro-história italiana, Rio de Janeiro, Civilização Brasileira, 2006.

Lins, Vera, Poesia e crítica, Rio de Janeiro, 7Letras, 2005.

Meireles, Cecília, Crônicas de educação, Leodegário A. de Azevedo Filho (ed.), Rio de Janeiro, Editora Nova Fronteira/Fundação Biblioteca Nacional, 2001.

Miceli, Sérgio, Intelectuais e classe dirigente no Brasil (1920-1945), São Paulo, DIFEL, 1979.

Motta, Rodrigo Patto Sá, Em Guarda contra o «Perigo Vermelho», São Paulo, Editora Perspectiva/FAPESP, 2002.

Paro, Maria Clara Bonetti, «Whitman in Brazil», Gay Wilson Allen y Ed Folsom (eds.), Walt Whitman and the World, Iowa City, University of Iowa Press, 1995: 128-146.

Pensamento da América, página semanal de $A$ Manhã, agosto 9 de 1941 a enero 8 de 1942, Rio de Janeiro, Biblioteca Nacional.

Pensamento da América, Suplemento panamericano de A Manhã, 1942-1944, Albany, NY, library of the University at Albany - SUNY.

Perrone, Charles, Brazil, Lyric, and the Americas, Gainesville, University Press of Florida, 2010. 
Pinheiro, Paulo Sérgio, Estratégias da Ilusão, São Paulo, Companhia das Letras, 1991.

Pizarro, Ana, Gabriela Mistral, Santiago de Chile, LOM Ediciones, Embajada de Brasil en Chile, 2005.

Ramos, Julio, Divergent Modernities, Durham y London, Duke University Press, 2001.

Ricardo, Cassiano, Viagem no tempo e no espaço, Rio de Janeiro, José Olympio, 1970.

Sasson, Anne Showstack, Gramsci’s Politics, Minneapolis, University of Minnesota Press, 1987.

Schwartzman, Simon, Maria Helena Bomeny y Vanda Ribeiro Costa, Tempos de Capanema, Rio de Janeiro/ São Paulo, Paz e Terra/EDUSP, 1984.

Segatto, José Antonio, José Paulo Netto, José Ramos Néto, Paulo César de Azevedo y Vladimir Sachetta, PCB (Memória Fotográfica, 1922-1982), São Paulo, Brasiliense, 1982.

Sevcenko, Nicolau, Orfeu extático na metrópole, São Paulo, Companhia das Letras, 1992.

Sodré, Nelson Werneck, A História da imprensa no Brasil, Rio de Janeiro, Civilização Brasileira, 1966.

Thornberry, Robert S., «Writers Take Sides: Stalinists Take Control», The Historian 62/3 (spring 2000): 590-605.

Vacca, Giuseppe, «La "quistione politica degli intellettuali" e la teoria marxista dello Stato nel pensiero di Gramsci», Franco Ferri (ed.), Politica e storia in Gramsci I, Roma, Editori Riuniti/Istituto Gramsci, 1977: 439-480.

Villareal, José Javier (trad.), Preparación para la muerte, de Manuel Bandeira, Mexico, D.F., Ed. UNAM, 2000.

Williams, Daryle, Culture Wars in Brazil, Durham y London, Duke University Press, 2001.

Whitman, Walt, Poetry and Prose, New York, Library of America, 1982.

Fecha de recepción: 2 de marzo de 2009

Fecha de aceptación: 23 de noviembre de 2009 


\section{CONJECTURAL FRONT: BRAZILIAN WRITERS ON THE LEFT AND THE ESTADO NOVO}

In the official newspaper of the Estado Novo, a dictatorship led by Getulio Vargas in Brazil from 1937 to 1945, a group of intellectuals organized a cultural section, "Pensamento da América», devoted to publishing translations of writers from across the Americas. Drawing on archival research, this article reconstructs the trajectory of this cultural section, from muted anti-fascism and Latin Americanism, in 1941, to playing a supporting role for Vargas's wartime foreign policy, from 1942 on. It is concerned, above all, with exploring the contexts that both opened the way and set the limits for the activities of the intellectuals responsible for "Pensamento da América».

Key words: Hegemony, intellectuals in Brazil, Ribeiro Couto, Manuel Bandeira, Vargas years. 